\title{
AVALIAÇÃO E A “PEDAGOGIA DO CONCEITO”: UM DIÁLOGO
}

\author{
Kelvlin Ferreira Medeiros \\ Graduando em Filosofia - UnB
}

Resumo:: O presente artigo tem por objetivo iniciar uma discussão sobre os mecanismos avaliativos e a "pedagogia do conceito", proposta metodológica desenvolvida por Sílvio Gallo. Para tanto, pretendo (i) expor elementos básicos sobre a "pedagogia do conceito" para, após isto, (ii) atinar a discussão sobre os problemas ligados aos mecanismos de avaliação e a pedagogia do conceito. Feito isto, pretendo, por último, (iii) trazer como sugestão de instrumento de avaliação os mapas conceituais, bem como trazer, de modo rápido, a fundamentação teórica por detrás destes.

Palavras-chaves: Pedagogia do conceito, mapas conceituais, Ensino de filosofia, Avaliação.

Abstract: The present article has as objective propose a discussion about the evaluation mechanisms and the "pedagogy of concept", a methodological proposal developed by Sílvio Gallo. For this, I pretend (i) expose the basic elements about the "pedagogy of concept" for, after it, (ii) guide the discussion for the problems attached to evaluation mechanisms and the pedagogy of concept. Since it is done, I pretend, at last, (iii) propose as suggestion of an evaluation instrument the conceptual maps and show, quickly, the theorical fundamentation of it.

Keywords: pedagogy of concept, conceptual maps, philosophy teaching, evaluation.

$1-$ A “pedagogia do conceito”

A “pedagogia do conceito” é uma proposta filosófico-pedagógica criada por Sílvio Gallo e exposta de uma maneira mais sistemática no livro Metodologia do Ensino de Filosofia (2012). De maneira geral, o livro procura pensar o ensino de filosofia como um problema filosófico e, a partir desta perspectiva, traz alguns apontamentos metodológicos para que o ensino de filosofia seja, propriamente, uma experiência com o conceito.

A abordagem de Gallo é feita por meio de uma apropriação da filosofia de Gilles Deleuze e Félix Guattari. Estes autores, em “O que é a filosofia?”, afirmam que a ideia constitutiva da filosofia, isto é, aquilo que propriamente a torna aquilo que ela é, é que ela experiencia e cria conceitos. Diferentemente das ciências, que visam construir um 
modelo de explicação dos fenômenos por meio de funções, e das artes, que se servem de afectos e perceptos, a filosofia busca criar ferramentas de compreensões no âmbito conceitual. Dito de outro modo, estes domínios do saber procuram, de diferentes maneiras, um modo de se relacionar com o mundo - e, de certa forma, explicá-lo. A filosofia, por sua vez, trata o objeto de investigação - seja ele qual for - não tentando explicar as relações entre um fenômeno e outro por meio de fórmulas (funções) ou criando imagens, músicas ou performances que tentam, de alguma maneira, capturar o mundo (afectos e perceptos), mas tentando se apropriar deste fenômeno do ponto de vista do próprio pensamento, sempre levando em consideração o motivo pelo qual aquele pensamento foi forçado, isto é, observando sempre o problema.

Desse modo, a "pedagogia do conceito", enquanto uma "metodologia" ${ }^{1}$ para o ensino de filosofia, pretende propiciar um local adequado para essa experiência com o conceito e com o problema. Assim, ao se propor uma didática, temos de, obviamente, traçar um plano que contemple estes dois pontos. E esta didática pode ser resumida em quatro pontos principais: (i) sensibilização; (ii) problematização; (iii) investigação e (iv) conceituação.

Na sensibilização (i), o professor é responsável por chamar a atenção do aluno, isto é, afetá-lo com o tema da aula. Isso, por sua vez, pode ser feito mediante a referência a problemas do dia-a-dia de seu aluno, ou por meio de filmes, músicas, textos, teatros, etc.

A problematização (ii), por sua vez, trata-se da etapa onde o objeto de afeto, isto é, aquilo que foi sensibilizado (o tema da aula), seja, agora, problematizado. Assim, o objetivo, neste passo, é fazer do tema um problema de modo que os alunos encontremse engajados.

A investigação (iii), então, trata-se do momento no qual o aluno visita e/ou revisita a história da filosofia buscando abordagens filosóficas para aqueles determinados problemas. Caso nada seja encontrado, o interessante é que o aluno

\footnotetext{
${ }^{1}$ Cabe aqui uma nota extremamente importante. Para Gallo, é importante notar que as metodologias, desde o seu nascimento, constituem-se como dispositivos de controle. Porém, a metodologia aqui proposta não entra nesse modelo como um dispositivo de controle, isto é, um algoritmo que engessa por completo o processo. A metodologia proposta por Gallo é, por assim dizer, mais um horizonte norteador, que pode eventualmente ser “contrariada” sem prejuízos para o processo como um todo.
} 
identifique alguns conceitos ou modos de lidar com os problemas de modo a propiciar a ele uma chave de leitura para abordar o problema de maneira filosófica.

Por fim, a conceituação (iv) é o momento no qual o aluno cria ou recria conceitos para "responder" os problemas suscitados nas etapas anteriores. O interessante é que estes mesmos conceitos podem vir a ser novamente temas das aulas, tornando-se, eles mesmos, objetos de sensibilização (i), problematização (ii), investigação (iii) e conceituação (iv).

Assim, a pedagogia do conceito, de modo geral, pressupõe um certo elemento subjetivo, tendo em vista que o processo de conceituação sempre será uma "nova” ${ }^{2}$ ou, por assim dizer, uma apropriação ressignificada dos conceitos aprendidos e apreendidos na etapa da investigação. Além disso, a proposta de Gallo também assume que o processo de ensino é uma abertura, uma espécie de cheque-em-branco, no qual ao professor cabe propiciar um ambiente "adequado" para que o aluno construa seus próprios conhecimentos e ao aluno cabe a iniciativa de se engajar ou não no processo; isto é, é um processo que deixa em aberto se haverá ou não o aprendizado, estabelecendo um papel ativo ao aluno.

Nesse sentido, embora esta didática esteja circunscrita como um modus operandi dentro de sala, ela não pode ser vista como um algoritmo, ou, para aproximar mais do linguajar de Gallo e Deleuze, um mecanismo de controle. Gallo afirma, em vários momentos de seu livro, que a metodologia proposta pela pedagogia do conceito não é uma didática prescritiva, que nos diz o que fazer. Ela é apenas um modelo geral que podemos ou não usar como pano de fundo para planejar as aulas de filosofia. Por este motivo que Gallo propõe o ensino de filosofia como uma "tática de resistência”. Mesmo que o ensino de filosofia, no contexto brasileiro, esteja inserido como uma política pública que teve de ser assegurada por meio de uma lei, isto não quer dizer que, na prática quotidiana, o ensino de filosofia deva se guiar pelos mesmos "mecanismos" que garantiram sua existência e sua permanência no contexto da educação brasileira. Porém, mesmo que em sala de aula, no contexto de uma “educação menor”, o ensino de

\footnotetext{
${ }^{2}$ Será sempre novo, pois o que motivou o aluno a ir atrás da resolução daquele problema e, em especial, a forma como ele "cria" este conceito é única. A investigação (iii) feita na história da filosofia foi apenas uma espécie de ferramenta para que ele mesmo pudesse criar uma forma de se relacionar com aquele determinado problema, podendo o problema ser solvido ou não.
} 
filosofia não pode se furtar de sua relação com o Estado. E, nesse sentido, o professor não pode se furtar de exercer algumas práticas como a avaliação.

Em sua Metodologia, Gallo não menciona um pano de fundo para pensar a avaliação do ensino sob essa perspectiva. E esse tema, por sua vez, tem se mostrado bastante caro à nossa pesquisa. Entretanto, não deixaremos esta dificuldade nos impedir de tentar tecer algumas considerações sobre o tema.

A pedagogia do conceito, desde o início, propõe o ensino de filosofia como um cheque em branco. Nesse sentido, Gallo procura desligar os termos "ensino” e “aprendizagem”, comumente utilizados para se falar de ensino. Para Gallo, o ensino não pode ser visto como um dispositivo de controle, isto é, mesmo que o ensino faça parte de uma política pública, que tem fins bem definidos, ele deve agir como uma tática de resistência, como uma educação menor. O termo educação menor é uma apropriação feita da leitura deleuziana das obras de Kafka. De modo geral, Kafka era um escritor que se encontrava em um ambiente hostil à sua obra; um tcheco escrevendo em alemão. Dentro de toda uma cultura que procurava fortalecer sua identidade nacional, se servindo da língua materna e da naturalidade para tanto, Kafka estava lá, escrevendo, e sendo considerado um “estrangeiro”. Por meio dessa leitura, então, Deleuze classifica a obra de Kafka como uma literatura menor, uma literatura de resistência. Gallo se serve dessa classificação e faz uma transposição conceitual para pensar o ensino de filosofia. Nesse sentido, o ensino de filosofia enquanto política pública é pensado como uma educação maior, ao passo que o ensino de filosofia que pode ser praticado no quotidiano - e ao qual Gallo defende -, a pedagogia do conceito, é uma educação menor, que sempre se encontra em uma relação tensa com os dispositivos burocráticos e regulatórios vigentes.

Assim, pensar o ensino de filosofia nos leva a analisar, mesmo que de maneira breve, estes dois âmbitos. Acima já tentamos expor, de maneira rápida, o ensino de filosofia enquanto uma educação menor. É bom lembrar também que não esgotamos essa análise, e que esta pode render muito mais do que as poucas páginas acima. Entretanto, para que possamos direcionar nossa discussão para o objetivo, é necessário fazer alguns cortes e tratar, também de maneira rápida, o ensino de filosofia enquanto educação maior. 
Enquanto política pública, o ensino de filosofia, podemos dizer, é regulamentado pelos documentos legais - em especial a LDB (lei de diretrizes e bases da educação) e, atualmente, os PCN (parâmetros curriculares nacionais). Não pretendo tratar diretamente destes documentos. Porém, salientamos que é extremamente importante estabelecer um diálogo com tais documentos. Sabemos também que, enquanto política pública, é necessário, de fato, um mecanismo de controle, um dispositivo que possa avaliar de maneira objetiva a eficiência de tal empreendimento. E, em meio a tudo isso, encontra-se o professor. Enquanto sujeito de uma educação maior, ele se encontra como um funcionário; já enquanto sujeito de uma educação menor, ele pode acabar por assumir uma função diferente. E em meio à essas duas “educações”, o professor se vê obrigado a realizar algumas atividades, tal como a aplicação de provas.

Nesse sentido é que a discussão sobre a avaliação e o ensino de filosofia se mostra importante: isso é algo sobre o qual o professor, enquanto sujeito de uma educação maior não pode se furtar. Talvez, num contexto de educação menor, essa prática pode até ser abolida; entretanto, se tratando da política pública, provavelmente o professor sofrerá sanções do órgão público responsável. Temos, então, um problema: como realizar a avaliação de modo que não prejudique ou simplesmente nulifique todo o esforço empreendido no contexto da educação menor, isto é, como avaliar tendo como pano de fundo a pedagogia do conceito?

Essa pergunta surge na investigação e toma lugar central. Tendo em vista que a pedagogia do conceito propõe um modelo de ensino ativo, que visa a propiciar ao aluno um ambiente favorável para sua experiência com o conceito, como podemos pensar um mecanismo de avaliação que dê suporte a esse tipo de abordagem filosófico-pedagógica; isto é, como podemos pensar num mecanismo de avaliação - que, do nosso ponto de vista, não é possível ser pensado fora do escopo de um dispositivo de controle - que minimamente dê conta de satisfazer os requisitos da pedagogia do conceito? A resposta não é fácil. E, em meio à algumas pesquisas, encontrei uma atividade que pode ser utilizada como um mecanismo de avaliação sem que arruíne por completo todo o esforço empreendido pela pedagogia do conceito. E este recurso é chamado de mapa conceitual. 


\section{2 - Mapas conceituais e aprendizagem significativa}

De modo geral, mapas conceituais são diagramas que expressam as relações entre conceitos ou as palavras que usamos para representar conceitos. Eles podem ser feitos partindo da análise de um único contexto ou até mesmo para expressar uma relação densa entre conceitos de um sistema filosófico. Todavia, embora os mapas conceituais possam ser utilizados para evidenciar a relação conceitual dentro de um sistema intrincado, ele não é estático.

Segundo Moreira (1988), mapas mentais não devem ser confundidos com redes semânticas, mapas mentais ou quadros sinópticos. O objetivo central dos mapas conceituais não é o de classificar conceitos, mas sim expressar o modo a partir do qual estes se relacionam. As regras para criar mapas conceituais são definidas a partir da preferência de cada um. Com efeito, o mais importante para a confecção dos mapas conceituais é expressar o modo a partir do qual os conceitos se relacionam, e não traçar um mapa conceitual decompondo um conceito em todos os seus inerentes (embora isto também possa ser feito).

Nesse sentido, para confeccionar um mapa conceitual é interessante tomar um conceito principal, isto é, o conceito a partir do qual todo o mapa se desdobrará e, a partir deste, traçar as relações que os demais conceitos possam ter com este conceito principal. O interessante da construção de um mapa conceitual é que ele não é autoexplicativo, pois, já que se trata da construção de uma relação entre conceitos, o significado que o educando dá a essas relações a partir do modo como ele as tece que é o ponto crucial da confecção de mapas conceituais. Nesse sentido, é necessário que o educando faça uma breve exposição do mapa explicitando as relações feitas - e, assim, poderemos ao menos ter uma ideia de qual foi o significado atribuído à relação e até mesmo aos conceitos utilizados. Por isso, o mapa conceitual se mostra um mecanismo eficaz para melhorar tanto a aprendizagem do aluno - possibilitando que o aluno possa ter uma aprendizagem significativa - quanto pode ser utilizado como estratégia avaliativa.

A aprendizagem significativa é uma teoria do processo de aprendizagem criada por David Ausubel, que, grosso modo, defende que uma aprendizagem é dita significativa quando um novo conhecimento adquire significado para o educando por meio de uma ancoragem em/com seus conhecimentos prévios. 
Para Ausubel, na medida em que o educando entra em relação com novos conhecimentos há dois tipos de processos de aprendizagem que podem ser desencadeados: a aprendizagem mecânica e a aprendizagem significativa.

A aprendizagem mecânica é aquela onde o novo conhecimento é meramente armazenado, isto é, copiado. Não há, neste processo, nenhum elemento interacional entre o novo conhecimento e os conhecimentos prévios do aluno, resultando, por assim dizer, na mera memorização, sem que este novo conhecimento adquira uma significação relevante para o aluno.

Já na aprendizagem significativa, há o diálogo entre os novos conhecimentos e os conhecimentos prévios de modo que os conhecimentos prévios, tomando a forma de subsunçores $^{3}$, servem como "ponte" para que os novos conhecimentos adquiram relevância e significação. Dito de outro modo, os novos conhecimentos, balizados com os subsunçores, adquirem um significado mais próximo da realidade do aluno e também modifica aquele conhecimento prévio, pois agora o educando possui uma outra estrutura para significar aquele conhecimento. Desse modo, há, na aprendizagem significativa, um processo constante de significação e ressignificação, o que culmina em uma aprendizagem e reaprendizagem constante, visto que o novo conhecimento também serve de subsunçor para que um outro conhecimento seja significado a partir deste e assim por diante.

Assim, “quanto mais se relaciona o novo conteúdo de maneira substancial e nãoarbitrária com algum aspecto da estrutura cognitiva prévia que for relevante, mais próximo se está da aprendizagem significativa” (Pellizari, Kriegl, Baron, Finck, Dorocinski. 2002, p. 39), este processo de aprendizagem que proporciona ao aluno que os novos conhecimentos adquiram relevância para o aluno tem em vista suas próprias experiências - e isto, por sua vez, implica que o aprendizado não será meramente mimético, mas que contará com um elemento subjetivo. Portanto, a aprendizagem significativa valoriza os conhecimentos prévios de modo a garantir a eles um papel fundamental: o de servir de subsunçor para que o novo conhecimento adquira uma significação mais próxima da experiência pessoal do aluno.

\footnotetext{
${ }^{3}$ Esta é a tradução do termo inglês subsume, utilizado por Ausubel para discorrer e descrever os conhecimentos prévios da estrutura cognitiva do aluno e o processo por meio do qual estes conhecimentos interagem uns com os outros.
} 
Os mapas conceituais, por assim dizer, podem ser utilizados, nesse sentido, como uma estratégia para ver como o aluno estabeleceu as relações entre os conhecimentos prévios e os novos conhecimentos, de modo a tornar mais explícito se realmente houve um processo de significação na aprendizagem. E, assim, parece que também pode ser utilizado como um mecanismo de avaliação graças ao diálogo e às semelhanças para com a pedagogia do conceito.

\section{3 - Considerações finais}

Vimos, neste artigo, que a discussão sobre o ensino de filosofia pode ser vista tanto do ponto de vista pedagógico quanto do ponto de vista filosófico. Sem desmerecer qualquer um destes domínios do saber, acreditamos que cada um tem ferramentas e modos para contribuir com a análise do tema, de modo que, quanto mais ferramentas possamos utilizar para realizar uma análise, melhor ela pode ser. Assim, ao analisar a avaliação e o ensino de filosofia, procuramos dispor de alguns destas ferramentas, de modo que a análise seja mais satisfatória. Nossa conclusão é a de que os mapas conceituais podem ser uma boa ferramenta, e que pode ser utilizada como um mecanismo de avaliação pelos professores que porventura decidirem se servir das ideias norteadoras da pedagogia do conceito. Entretanto, salientamos que o mero uso de mapas conceituais como estratégia avaliativa não é o suficiente para que a educação menor proposta por Gallo seja efetivamente posta em prática. Alertamos para o fato de que um dispositivo de avaliação tem de ser significado positivamente pelo professor, de modo a não fazer dele apenas uma mera droga para consumo ${ }^{4}$. Gallo nos incentiva a valorizar o processo de aprendizagem em detrimento do resultado, de modo que, assim, e somente assim, podemos realmente atingir um dos objetivos (o qual consideramos o mais importante) da pedagogia do conceito: ensinar um modo pelo qual os alunos possam se apropriar de conceitos e se servir destes para análises de diversas naturezas.

\section{Referências}

\footnotetext{
${ }^{4}$ Para mais sobre isso ler o texto "Droga: o ponto, boca de fumo: a escola. Uma crônica perversa sobre avaliação”. Ampliar a referência da citação. (não entendi aqui)
} 
GALLO, Sílvio. Metodologia do Ensino de Filosofia. Editora Papirus, 2012.

MOREIRA, Marco Antonio. Mapas conceituais e aprendizagem significativa. In: $O$ ENSINO, Revista Galáico Portuguesa de Sócio Pedagogia e Sócio-linguística. Pontevedra/Galícia/Espanha e Braga/Portugal, nº 23 a 28: 1988.

PELIZZARI, Adriana; KRIEGL, Maria de Lurdes; BARON, Márcia Pirith; FINCK, Nelcy Teresinha Lubi; DOROCINSKI, Solange Inês. Teoria da aprendizagem significativa segundo Ausubel. In: Revista PEC, Curitiba, v. 2, n.1, páginas 37-42, jul 2001-2002.

https://projetopaideia.wordpress.com/2012/12/11/droga-o-ponto-boca-de-fumo-aescola-uma-cronica-perversa-sobre-avaliacao/ - acesso em 09/10/2015, às 21:48 